\title{
Improvement of Water Resistance and Mechanical Properties of Fast-growing Poplar with Bio-based Isobornyl Methacrylate Monomer
}

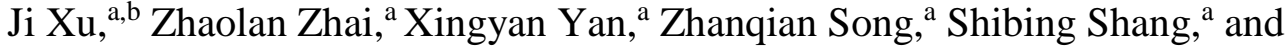 \\ Xiaoping Rao ${ }^{\mathrm{a}, \mathrm{c}, *}$
}

\begin{abstract}
Fast-growing poplar has become an extensively planted fast-growing forest tree species because of its short plantation rotation, lightweight character, and strong adaptability. However, fast-growing poplar usually exhibits some disadvantageous properties, such as inferior mechanical properties, high hygroscopicity, and poor dimensional stability, which limits its applications to a great extent. Herein, a simple method for improving the water resistance and mechanical properties of fast-growing poplar wood using the biobased monomer isobornyl methacrylate (IBOMA) was investigated. Wood/PIBOMA composites were prepared by impregnating the wood matrix with IBOMA ethanol solution, and then the IBOMA in the wood matrix was heated to initiate in situ polymerization. Field emission scanning electron microscopy (FE-SEM) and X-ray diffraction (XRD) were used to investigate the properties of fast-growing wood/PIBOMA composites. The results showed that the IBOMA successfully penetrated the wood structure and polymerized in the cell walls and cell lumens. Thereby, the water resistance and mechanical properties of the fastgrowing poplar were effectively improved. In addition, the water uptake of the wood decreased from $168.3 \%$ to $35.8 \%$ after impregnation with the $90 \%$ IBOMA solution. The modulus of rupture (MOR), modulus of elasticity (MOE), and compression strength (CS) of the $90 \%$ wood/PIBOMA composites were increased by $82.7,28.6$, and $2.3 \%$, respectively.
\end{abstract}

Keywords: Bio-based rigid monomer; Fast-growing poplar; Vacuum impregnation method; Mechanical properties; Water resistance.

Contact information: a: Institute of Chemical Industry of Forest Products, CAF; Key Laboratory of Biomass Energy and Material, Jiangsu Province; Co-Innovation Center of Efficient Processing and Utilization of Forest Resources, Jiangsu Province; Key Laboratory of Chemical Engineering of Forest

Products, National Forestry and Grassland Administration; National Engineering Laboratory for Biomass Chemical Utilization, Nanjing, 210042, China; b: Nanjing Forestry University, Nanjing, 210037, China; c:

Research Institute of Forestry New Technology, CAF, Beijing, 100091, China;

* Corresponding authors: rxping2001@163.com

\section{INTRODUCTION}

As a natural renewable material, wood has been widely used in construction, furniture, and decoration for a long time because of its lightweight nature, unique aesthetics, high mechanical strength, and ease of processing (Li et al. 2011; Reis et al. 2018; He et al. 2019). Due to the low growth rate of natural forests and the logging restrictions of various countries, the supply of high-quality wood is rapidly decreasing. However, the consumption of wood is dramatically increasing annually (Li et al. 2013; Qiu et al. 2018). Thus, fast-growing forest plantations have attracted considerable attention because of their short growth cycle and rich growing stock (Wang et al. 2019). 
Additionally, fast-growing forest plantations have been widely used as an important alternative to natural wood. However, fast-growing plantation woods generally have some inherent disadvantages, including inferior mechanical strength, weak water resistance, and poor dimensional stability, which severely limit their application (Ding et al. 2013; Cubbage et al. 2014; Hazarika et al. 2014; Liu et al. 2019). Among them, fast-growing poplar wood, as a typical fast-growing tree species, also has the above defects. Therefore, the preparation of fast-growing poplar with strong overall performance has been given more attention, and a variety of chemical modification methods have been proposed. Among them, acetylation modification is a typical method to improve wood properties by reacting with wood cell wall components (Chang and Chang 2002; Li et al. 2009; Himmel and Mai 2015). In addition, the overall performance of wood can be improved by filling both the cell walls and cell lumens of wood, using such methods as paraffin modification (Scholz et al. 2010; Brischke and Melcher 2015), 1.3-dimethylol-4.5dihydroxyethyleneurea (DMDHEU) modification (Jiang et al. 2014; Emmerich et al. 2019), thermosetting resin modification (Huang et al. 2013; Tao et al. 2019), and organic monomer modification (Kowalski et al. 2002; Dong et al. 2015; Wang et al. 2018). Although wood composites with excellent properties can be prepared by the above methods, many wood composites are harmful to the environment and human body during processing and application. Therefore, an increasing amount of recent research has focused on the preparation of green wood polymer composites (WPCs).

Wood polymer composites are prepared by impregnating wood with monomers, initiators, or prepolymers (Jiang and Kamdem 2004; Ghorbani et al. 2019). In recent years, biological chemicals derived from renewable resources have been used as wood modifiers. For instance, furfuryl alcohol has been used to modify biomass-derived chemicals (Kong et al. 2018), rosin has been used to modify renewable resources (Dong et al. 2016), and rosin derivatives have been used for modification (Dong et al. 2019). The water resistance and mechanical properties of poplar wood have been improved by the impregnation of rosin and its derivatives and the wood composites of furfuryl alcohol possess improved dimensional stability over the control wood. However, the modulus of rupture experienced a minor reduction (Dong et al. 2016, 2019; Kong et al. 2018).

Turpentine is a type of rich renewable resource as an exudate of pines. Turpentine is a liquid mixture composed of $\alpha$-pinene, $\beta$-pinene, and camphene. There are essentially one to three rings or bridged-ring rigid structures in these compounds, which endows its derivatives with excellent heat resistance and water resistance (Dubey and Gupta 2017). Thus, turpentine is a promising alternative for the preparation of WPCs. Herein, a new method for the preparing WPCs using turpentine derivatives as modifiers was studied. Isobornyl methacrylate (IBOMA, its structure is shown in Scheme 1) has been synthesized by addition esterification of camphene with methacrylic acid. IBOMA has good fluidity at room temperature and has the advantages of insolubility in water and low toxicity. It is a monomer with excellent hardness and pliability. More importantly, the IBOMA has a double bond and special alkyl structure and it can self-polymerize to form polymers with unique properties at low temperature ( $\mathrm{Xu}$ et al. 2017). Its polymer (PIBOMA) is a transparent polymer resin that can be used as an optical material. IBOMA has been applied to heat-resistant organic sheets, optical fibers, adhesives, powder coatings, and high solid content coatings. It can also be used as a reactive diluent for ultraviolet (UV) curable coatings ( $\mathrm{Xu}$ et al. 2017). 


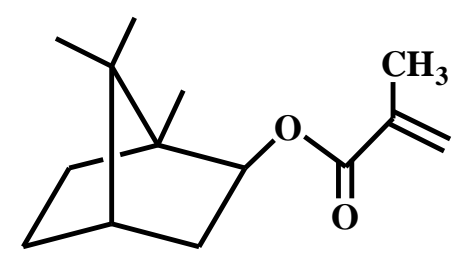

Isobornyl methacrylate

Scheme 1. Structure of IBOMA

In this work, wood/PIBOMA composites were prepared by impregnating wood with IBOMA and heating it in situ. The microstructure, dimensional stability, water resistance, and mechanical properties of wood polymeric composites were investigated.

\section{EXPERIMENTAL}

\section{Materials}

Sapwood of fast-growth poplar (Populus spp.) was obtained from a plantation located in the Henan Province, Zhengzhou, China. The IBOMA was purchased from Eternal Materials Co., Ltd. (Zhuhai, China). Azobisi sobutyronitrile (AIBN) was obtained from Aladdin Reagent Co., Ltd. (Shanghai, China). Ethyl alcohol (EtOH) was purchased from Xilong Scientific Co., Ltd. (Guangzhou, China). All reagents were used as received.

\section{Methods}

Preparation of wood/PIBOMA composites

Measurements of dimensional stability and water resistance tests were performed with 5 replicates of wood samples with dimensions of $20 \mathrm{~mm} \times 20 \mathrm{~mm} \times 20 \mathrm{~mm}(\mathrm{R} \times \mathrm{T} \times$ $\mathrm{L})$. The size of end-matched samples was $20 \mathrm{~mm} \times 20 \mathrm{~mm} \times 300 \mathrm{~mm}(\mathrm{R} \times \mathrm{T} \times \mathrm{L})$ for modulus of rupture (MOR) and modulus of elasticity (MOE) tests, and $20 \mathrm{~mm} \times 20 \mathrm{~mm} \times$ $30 \mathrm{~mm}(\mathrm{R} \times \mathrm{T} \times \mathrm{L})$ for the compression strength $(\mathrm{CS})$ test. Before impregnation, all samples were oven-dried at $105 \pm 1{ }^{\circ} \mathrm{C}$ until a constant weight was reached, and the weights and dimensions were recorded.

The impregnation solutions consisted of IBOMA, AIBN, and EtOH. The dried wood samples were immersed into the isobornyl methacrylate ethanol solutions with 30 , $50,70$, and $90 \mathrm{wt} \%$ concentrations using a vacuum chamber (0.095 $\mathrm{MPa}, 30 \mathrm{~min})$. Then, the samples and solutions were placed at a normal temperature and pressure for $24 \mathrm{~h}$. After the impregnations, the samples were first dried at $25^{\circ} \mathrm{C}$ for $2 \mathrm{~h}$ and then cured in an oven at $60{ }^{\circ} \mathrm{C}$ for $24 \mathrm{~h}$, allowing full polymerization of the isobornyl methacrylate within the wood. Afterward, the oven-dry weight and dimensions of the wood samples were remeasured.

\section{Characterization of control and wood/PIBOMA}

The morphology of the control and wood/PIBOMA samples were characterized using a Hitachi Regulus 8200 (Tokyo, Japan) field emission scanning electron microscope (FE-SEM). A sliding microtome (YAMATO REM-710, Tokyo, Japan) was used to obtain the cross-sections of the control and treated wood samples with a thickness of 15 to $20 \mu \mathrm{m}$, and then the samples were mounted on conductive adhesives, sputter coated with gold (SCD 005; Sputter Coater, Witten, Germany), and observed at a voltage of $5 \mathrm{kV}$. 
The control and wood/PIBOMA samples were milled to powders. Fourier transform infrared (FTIR) spectra for the powder samples were recorded on a Nicolet iS10 spectrometer (Thermo Scientific, Waltham, MA, USA) over the wavenumber range of 400 to $4000 \mathrm{~cm}^{-1}$.

The crystalline structures of the control and wood/PIBOMA samples were analyzed by X-ray diffraction (XRD) (Bruker D8 FOCUS Advance diffractometer, Karlsruhe, Germany). The equipment parameters were as follows: voltage $40 \mathrm{kV}$, electric current 40 $\mathrm{mA}$, and $2 \theta$ scan range from $5^{\circ}$ to $40^{\circ}$ with a scanning speed of $2^{\circ} / \mathrm{min}$.

\section{Properties measurement}

The weight percent gain (WPG) of the wood/PIBOMA samples was calculated using Eq. 1,

$$
\mathrm{WPG}(\%)=\left(W_{2}-W_{1}\right) / W_{1} \times 100
$$

where $W_{1}(\mathrm{~g})$ and $W_{2}(\mathrm{~g})$ are the oven-dried weight of the wood samples before and after the impregnation modification, respectively.

Both the control and modified wood were immersed in deionized water for 5 days, and the radial, tangential, and volumetric swelling $(S)$ were measured using a vernier caliper $( \pm 0.01 \mathrm{~mm})$. The volumetric swelling was calculated according to the following Eq. 2. The anti-swelling efficiency (ASE) was calculated by Eq. 3 and the dimensional stability was evaluated by the measurement of ASE,

$$
\begin{aligned}
& S(\%)=\left(V_{2}-V_{1}\right) / V_{1} \times 100 \\
& \operatorname{ASE}(\%)=\left(S_{\mathrm{u}}-S_{\mathrm{t}}\right) / S_{\mathrm{u}} \times 100
\end{aligned}
$$

where $V_{1}\left(\mathrm{~cm}^{3}\right)$ and $V_{2}\left(\mathrm{~cm}^{3}\right)$ are the volume of wood samples before and after 5 days of immersion in deionized water, respectively, $S_{\mathrm{u}}(\%)$ is the volumetric swelling of the control sample, and $S_{\mathrm{t}}(\%)$ is volumetric swelling of the modified sample.

Meanwhile, after different time intervals, the weight of the control and wood/PIBOMA samples immersed in deionized water was measured. Water uptake (WU) of the wood sample was calculated based on the weight of the sample before and after the water soaking. The WU can be calculated by Eq. 4,

$$
\mathrm{WU}(\%)=\left(W_{3}-W_{2}\right) / W_{2} \times 100
$$

where $W_{3}(\mathrm{~g})$ is the weight of wood sample immersed in deionized water.

The MOR, MOE, and CS of all control and wood/PIBOMA samples were measured using a CMT4000 microcomputer control electronic universal testing machine (Shenzhen Xinsansi Instrument Co., Ltd., Shenzhen, China). The MOR, MOE, and CS of all the control and wood/PIBOMA samples were tested according to the following Chinese standards: method for determination of the modulus of elasticity in static bending of wood as per GB/T 1936.2 (2009) and method of testing in the compression perpendicular to grain of wood as per GB/T 1935 (2009).

The contact angle of the wood sample was measured with a contact angle apparatus (DSA100; Kruss Scientific Instruments, Hamburg, Germany). Four samples were tested for each of the control and wood/PIBOMA samples. Deionized water droplets in the amount of $3 \mu \mathrm{L}$ were dropped on the surface of each wood sample with a micro-syringe, and the change in the contact angle value of the wood sample was recorded within 3 min. Each sample was tested 3 times. 


\section{RESULTS AND DISCUSSION}

The structures of PIBOMA, the control, and wood/PIBOMA samples at different IBOMA concentrations were characterized by attenuated total reflectance (ATR)-FTIR, and the results are shown in Fig. 1. For the control wood samples, the transmittance peaks can be assigned as follows: the band at $3355 \mathrm{~cm}^{-1}$ was assigned to the $\mathrm{O}-\mathrm{H}$ stretching; the absorption band at $2898 \mathrm{~cm}^{-1}$ was assigned to the $\mathrm{C}-\mathrm{H}$ stretching vibration; the band at $1733 \mathrm{~cm}^{-1}$ was assigned to the $\mathrm{C}=\mathrm{O}$ stretching of the acetyl group; the absorption band at $1593 \mathrm{~cm}^{-1}$ and $1505 \mathrm{~cm}^{-1}$ was assigned to the aromatic skeletal vibration, and the band at $1030 \mathrm{~cm}^{-1}$ was the primary alcohol. For the modified wood samples, the three absorption peaks of the wood samples were prominent, such as bands at $2950 \mathrm{~cm}^{-1}$ of $-\mathrm{CH}_{3}$ asymmetrical stretching vibrations, $2867 \mathrm{~cm}^{-1}$ of $-\mathrm{CH}_{2}$ symmetrical stretching vibrations, and $1714 \mathrm{~cm}^{-1}$ of $\mathrm{C}=\mathrm{O}$ stretching vibrations (Pandey 1999; Dong et al. 2014; Chang et al. 2015; Gao et al. 2015). Furthermore, in comparison to the ATR-FTIR spectra of the control, the peak at $1714 \mathrm{~cm}^{-1}$ of the $\mathrm{C}=\mathrm{O}$ stretching vibrations became sharper, and this trend was more pronounced as the concentration of IBOMA increased. The results demonstrated that the IBOMA penetrated the wood. Moreover, as the concentration of IBOMA increased, the amount of IBOMA filled in the wood cells also increased. The FTIR spectra provided no evidence for new peaks in the modified wood samples, which could be attributed to the in situ polymerization of IBOMA in the wood cell lumens, cell corners, middle lamella, and partly infiltrated wood cell walls.

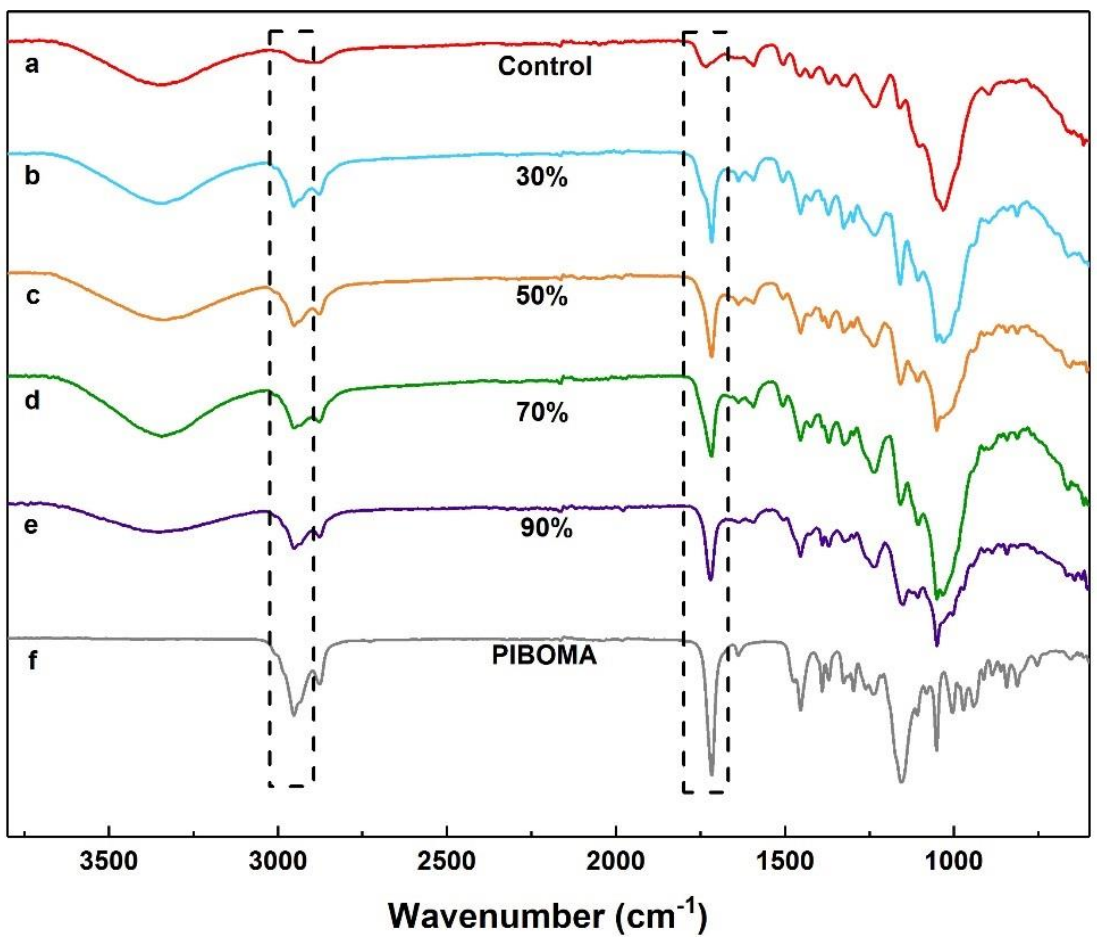

Fig. 1. ATR-FTIR spectra of PIBOMA, control, and wood/PIBOMA samples at different concentrations of IBOMA

Figure 2 shows the FE-SEM images of the cross-sections for the control and wood/PIBOMA samples. The natural porous structure of the control wood samples with irregular cell shapes can be observed from Fig. 2a. For the modified wood samples with 
$30 \%, 50 \%$, and 90\% IBOMA in Figs. 2b, c, and d, respectively, after impregnation of the IBOMA treatment, the structure of the wood was well-preserved and the volume of lumens in the wood/PIBOMA samples was evidently reduced, suggesting that polymerization of IBOMA partially occurred in the lumens and PIBOMA adhered to the cell structure of all modified wood samples. Because the IBOMA was filled into the wood, the physical and mechanical properties of the modified wood were improved. In addition, when the mass concentration of IBOMA increased from 30 to $50 \mathrm{wt} \%$, then to $90 \mathrm{wt} \%$, the amount of PIBOMA in the filled cell lumens and cell wall increased, and the pore area of the cell lumen decreased gradually.

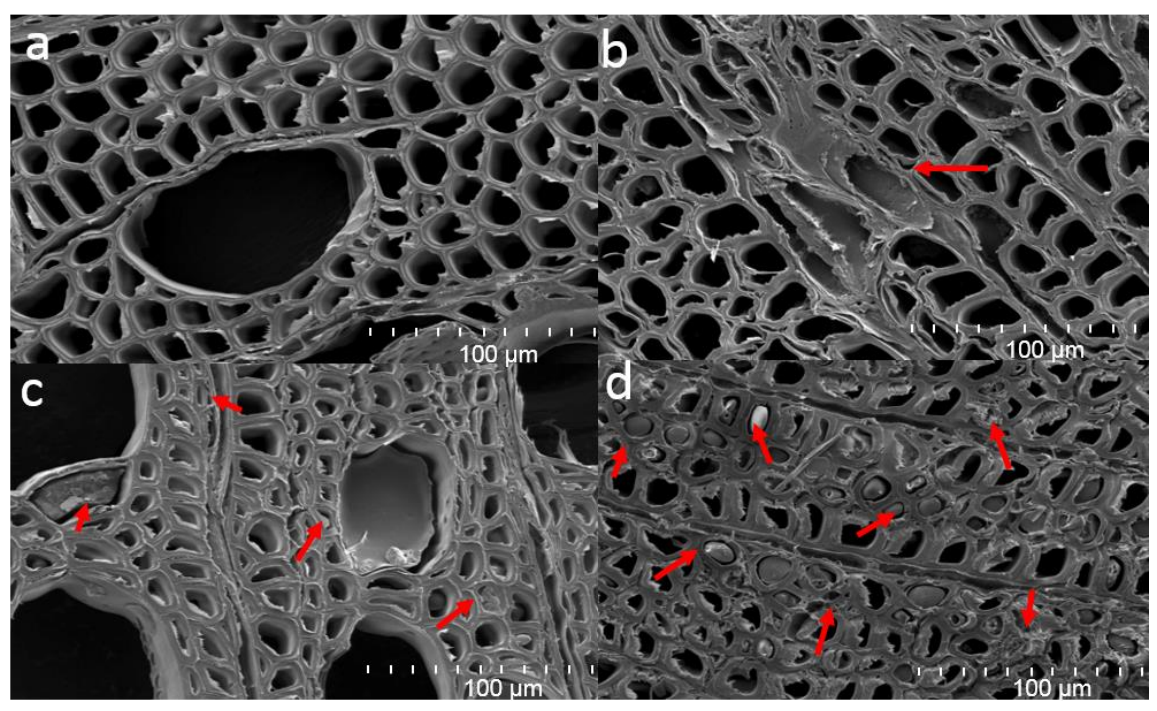

Fig. 2. FE-SEM images of (a) control wood, (b) wood/PIBOMA with $30 \%$, (c) wood/PIBOMA with $50 \%$, and (d) wood/PIBOMA with $90 \%$

The XRD patterns of PIBOMA, the control, and modified wood samples are shown in Fig. 3. The control wood sample showed a distinct peak (cellulose crystal diffraction, 101) at $15.8^{\circ}$, a position that was characteristic of the amorphous cellulose. The most obvious diffraction peak at the angle of $22.0^{\circ}$ with the curve of the control wood sample was assigned to the (002) crystal planes of the cellulose of wood. At the same time, the diffraction peaks (101) of 30\%, 50\%, 70\%, and 90\% IBOMA modified wood shifted from $15.8^{\circ}$ to $15.3^{\circ}, 15.1^{\circ}, 15.0^{\circ}$, and $14.9^{\circ}$, respectively. The reason for this shift might be because the PIBOMA is a glassy material with an amorphous nature, which showed a broad diffraction peak centered at $15.0^{\circ}$ (inset of Fig. 3). Moreover, the degree to which the diffraction peak shifted to the left increased with increasing IBOMA concentration. However, the trend of the distinct diffraction peak (002) of all modified woods at $21.99^{\circ}$ remained the same as that of the control wood, which indicated that the infiltration and solidification of IBOMA might have no remarkable effect on the structure of wood cellulose. The effect within the wood was physical expansion (Nirmala et al. 2013; Dong et al. 2015; Han et al. 2015). 


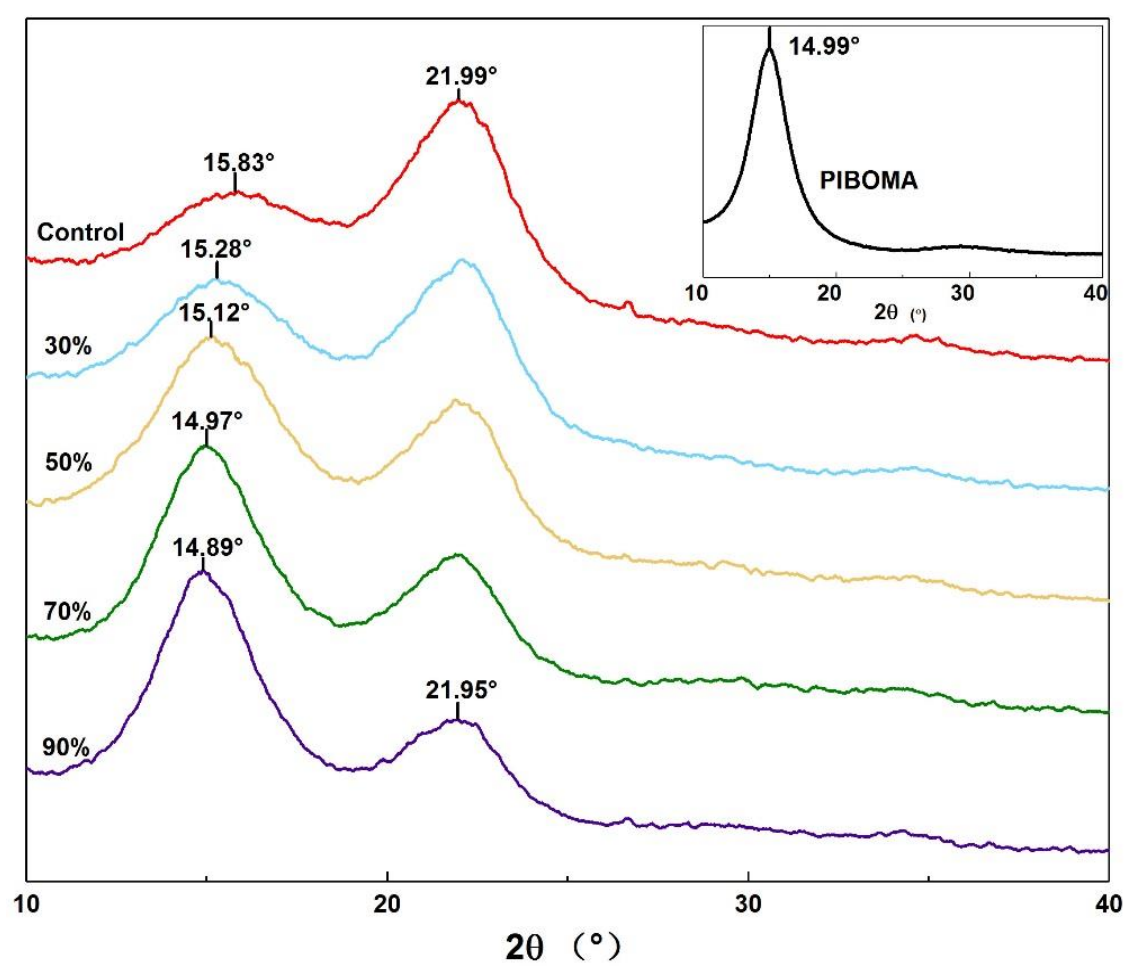

Fig. 3. XRD patterns of PIBOMA, control, and wood/PIBOMA samples: (a) Control wood, (b) wood/PIBOMA with $30 \%$, (c) wood/PIBOMA with $50 \%$, (d) wood/PIBOMA with $70 \%$, (e) wood/PIBOMA with $90 \%$, and (f) PIBOMA

Because IBOMA was cured and filled into the wood, the physical and mechanical properties of wood were improved. The wood samples were treated by IBOMA, and the weight percent gain (WPG) of the wood increased from 25.3 to $103.6 \%$. For the wood samples treated by $90 \%$ IBOMA, the density increased $100.2 \%$ from 0.443 to $0.887 \mathrm{~g} / \mathrm{cm}^{3}$, as shown in Figs. $4 \mathrm{a}$ and $\mathrm{b}$. The ASE was used to evaluate the dimensional stability of the modified wood samples. Larger ASE values corresponded with higher dimensional stability of the wood. The results are shown in Fig. 4d. After being immersed in water for 5 days, the volumetric swelling of the $90 \%$ IBOMA-modified wood decreased $12.9 \%$. The dimensional stability of the wood/PIBOMA composites was $1.3 \%, 4.4 \%, 7.2 \%$, and $12.9 \%$, respectively. In fact, the PIBOMA could only contribute to the dimensional stability of the wood when it was partly immersed in the cell walls, while the part deposited in the cell lumen could not contribute to dimensional stability (Kong et al. 2018). This meant that after the immersion treatment, only a small amount of IBOMA monomers entered the cell wall, and most of them were deposited in the cell lumen. 

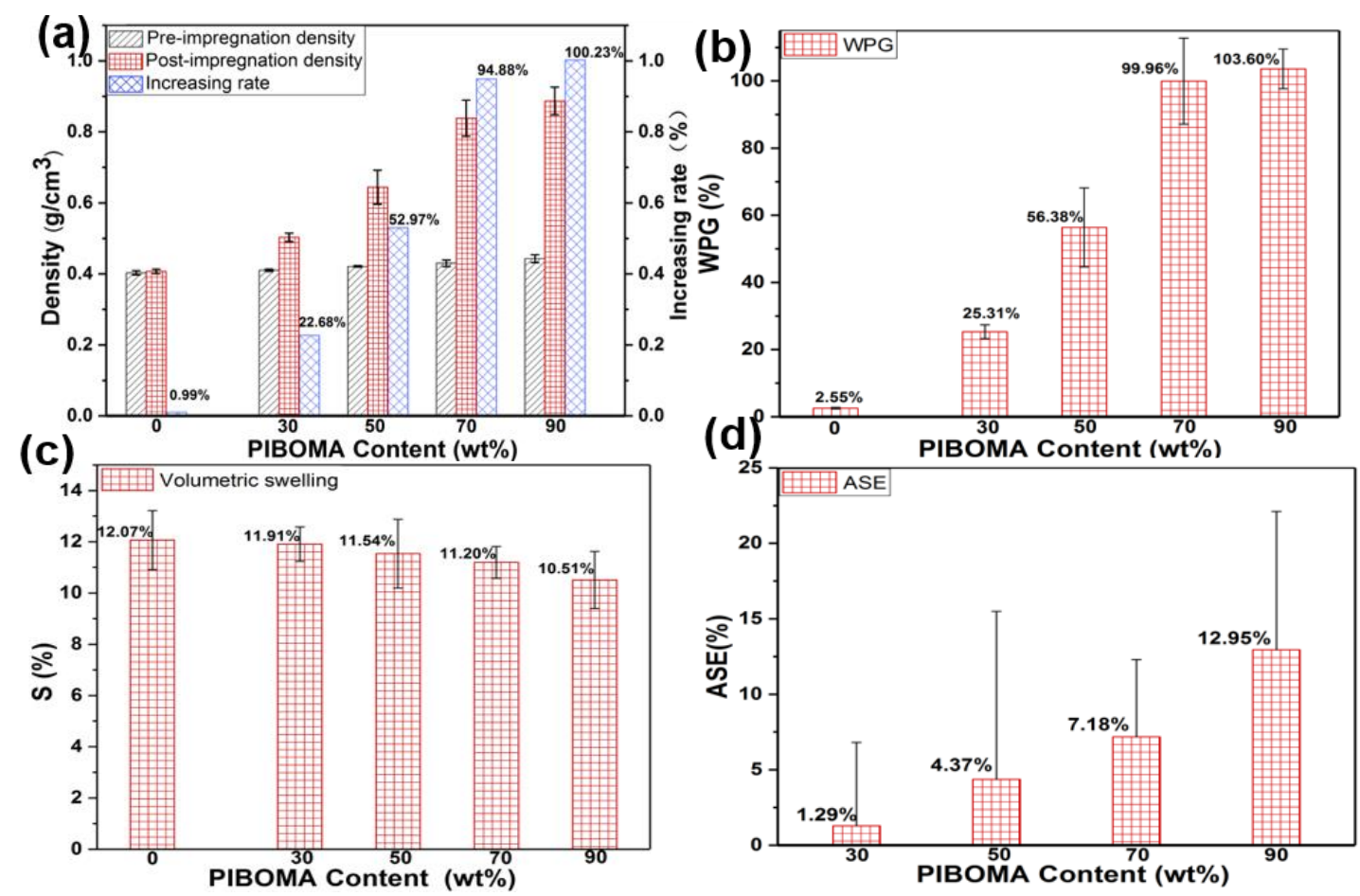

Fig. 4. Physical properties of wood samples. (a) the density, (b) the WPG, (c) the $S$, and (d) the ASE of the control and wood/PIBOMA samples

The mechanical properties of the modified wood are shown in Fig. 5. It is well known that the mechanical properties of wood are positively related with the density of wood. Moreover, the heat treatments can result in a decrease in many strength properties of the wood (Van Gelder et al. 2006; Xie et al. 2013). Compared to the control wood, the MOR and MOE of the $90 \%$ IBOMA modified wood were increased by $82.7 \%$ and $28.6 \%$, respectively, but CS only increased $2.3 \%$. The MOR, MOE, and CS of the modified wood increased with the increase of IBOMA concentration. These results indicated that improvement of the mechanical properties in the wood samples can be attributed to the efficient filling of IBOMA and to the modification treatment only at low temperatures. In general, the MOR and MOE of other wood modifications, such as maleic rosin and furfuryl alcohol wood (Kong et al. 2018; Yang et al. 2018), were slightly improved, and partly reduced. However, the CS of the modified wood samples increased noticeably. 

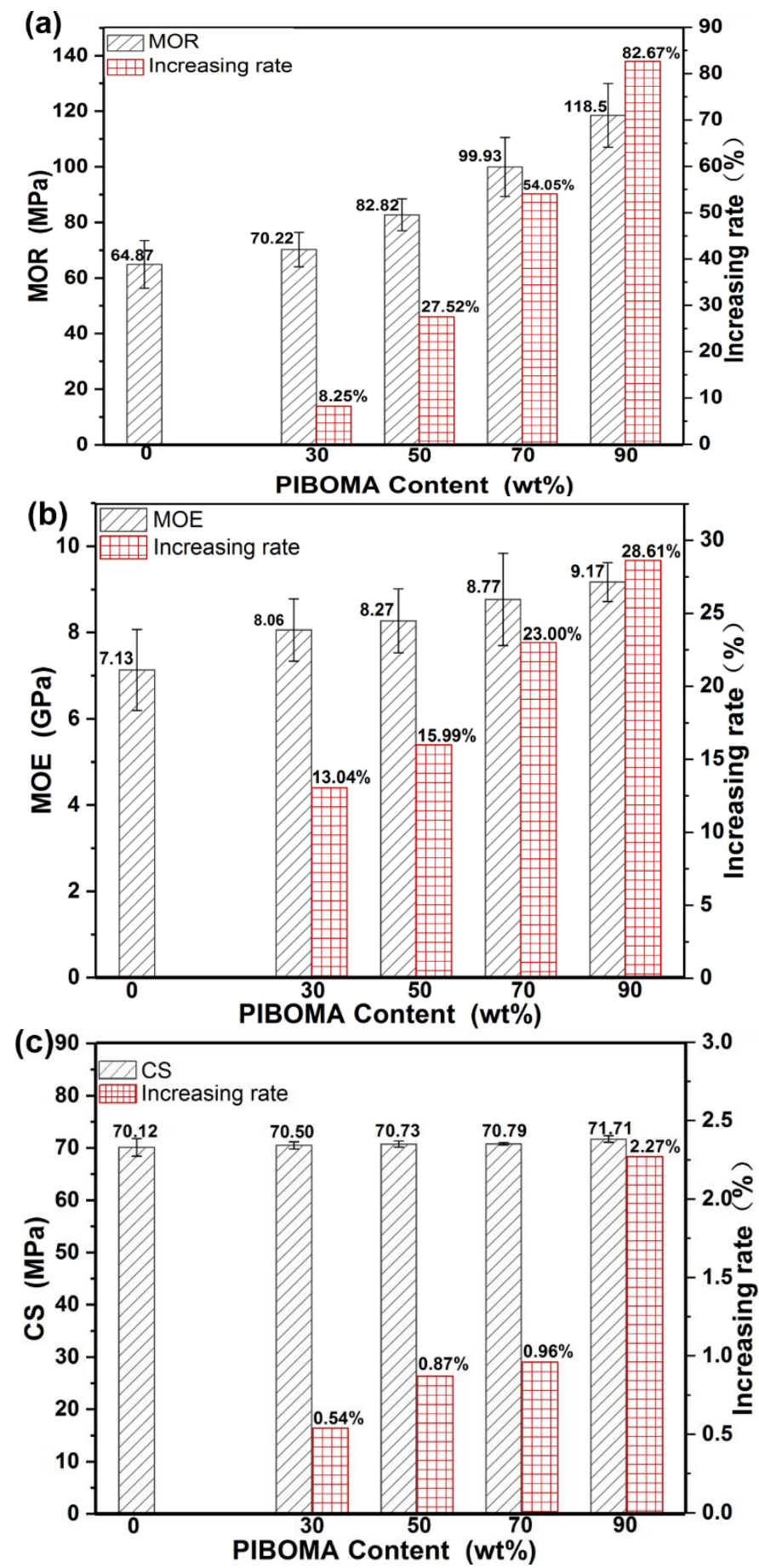

Fig. 5. Mechanical properties of control and wood/PIBOMA samples: (a) MOR, (b) MOE, and (c) CS

The water resistance of the control and wood/PIBOMA samples are shown in Fig. 6 . The contact angles of the control and wood/PIBOMA samples at $15 \mathrm{~s}, 105 \mathrm{~s}$, and $180 \mathrm{~s}$ are displayed in Fig. 6a. The contact angle of the modified wood increased with the increase of IBOMA concentration. Dynamic wettability of the modified wood was evaluated by testing the change in contact angle within $3 \mathrm{~min}$. The contact angle of the control wood samples decreased rapidly within the initial $15 \mathrm{~s}$. The contact angle of the modified wood samples decreased slightly after $15 \mathrm{~s}$. The contact angle of wood in the control group 
changed from $68.4^{\circ}$ to $27.8^{\circ}$ in $3 \mathrm{~min}$, which implies are reduction of $56.3 \%$. However, the contact angle of the $90 \%$ IBOMA-modified wood decreased from $113.8^{\circ}$ to $111.1^{\circ}$, which was a decrease of only $2.4 \%$. The results demonstrated that the immersion of IBOMA reduced the wettability of wood.

To further study the water resistance of the modified wood, the WU of the control and wood/PIBOMA samples as a function of time at room temperature was measured, and the corresponding results are shown in Fig. 6c. The water absorption of both the control and wood/PIBOMA samples increased with time. As the immersion time increased, more water permeated into the wood voids and capillaries, resulting in an increase in water uptake capacity (Wang et al. 2017). After being immersed for 12 days, the WU of the control sample was $168.3 \%$. Interestingly, the water absorption rate of the $90 \%$ IBOMA alcohol solution modified wood was only $35.8 \%$. after being immersed for the same time. The results showed the infiltration of water for the $90 \%$ IBOMA alcohol solution modified wood dramatically decreased. This meant that the polymerization and immersion in cell lumen and cell walls of the IBOMA effectively improved the water resistance of wood. The above results revealed that the IBOMA was not only a green wood modifier but also an effective wood modifier.

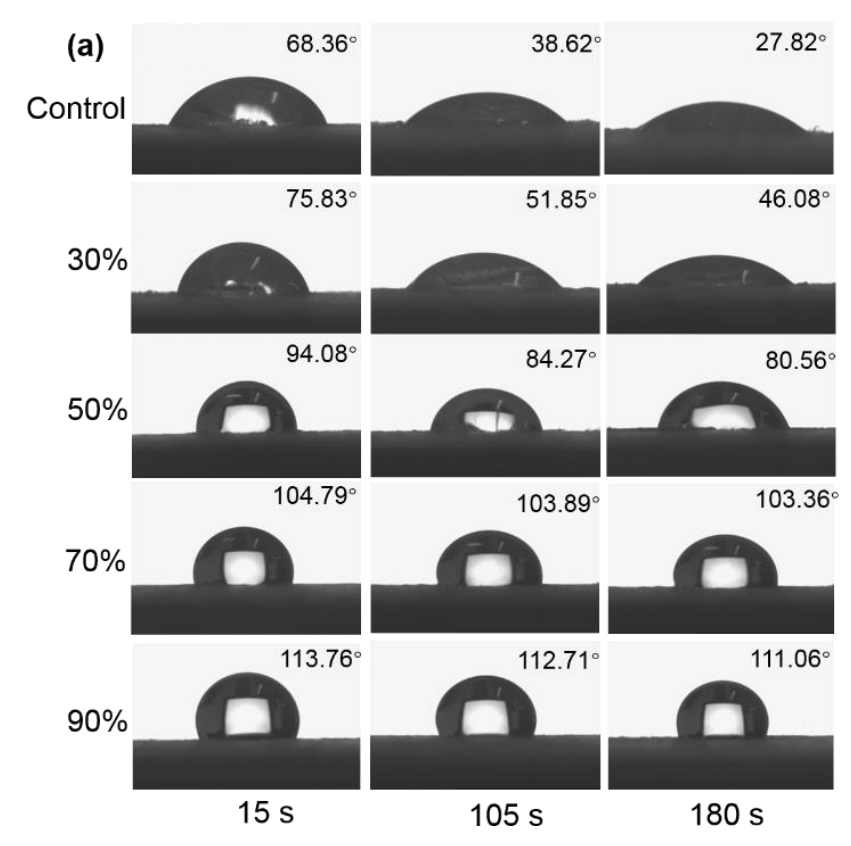



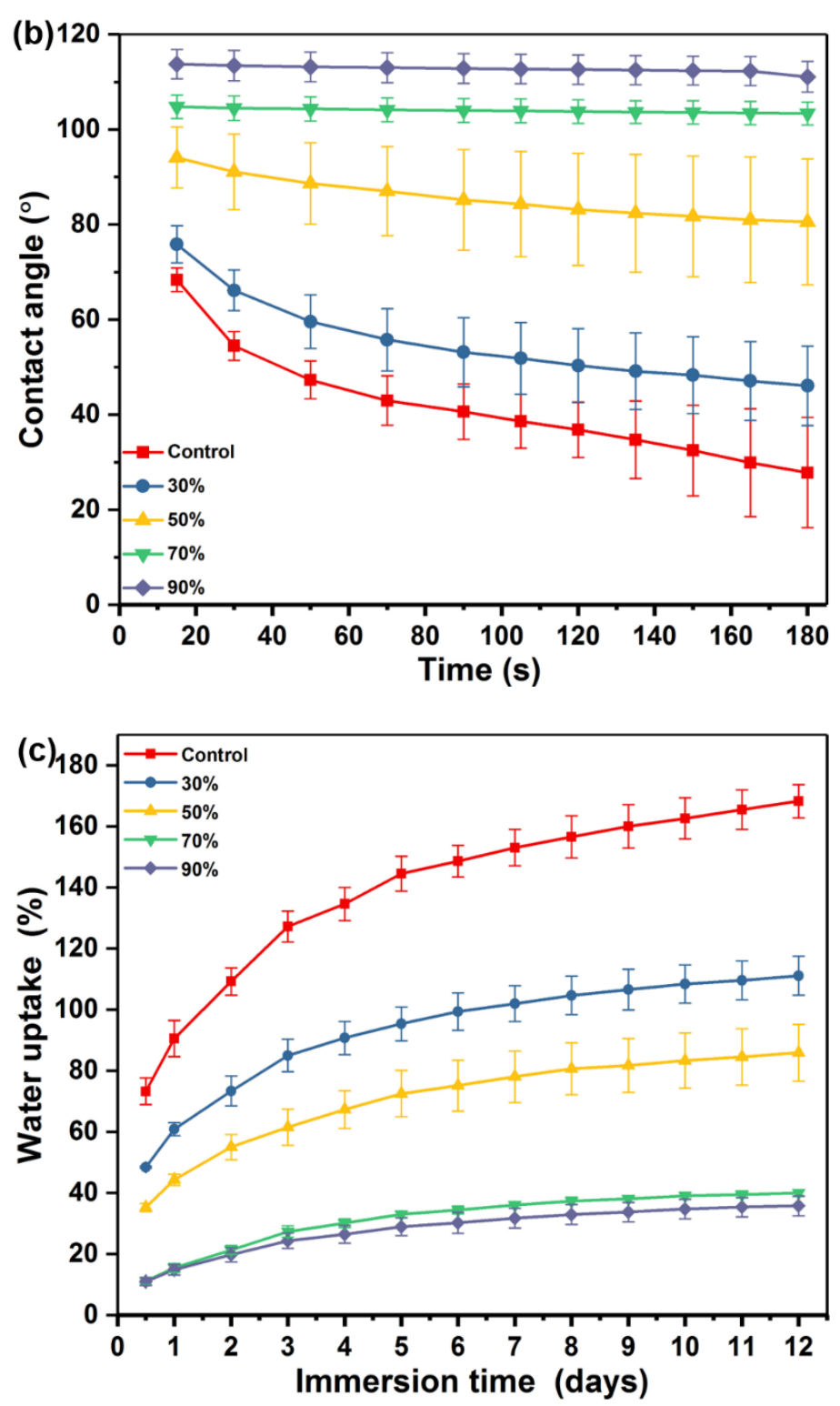

Fig. 6. Photographs of contact angle and water uptake of control and wood/PIBOMA samples: (a) contact angle, (b) dynamic wettability, and (c) water uptake

\section{CONCLUSIONS}

1. Wood/PIBOMA composites with strong overall properties were prepared by using a green and low energy consumption method with natural resources as raw material. The biobased monomer with a rigid core, IBOMA, can penetrate fast-poplar wood. It can further fill in both the cell wall and cell lumen of the fast-growing wood.

2. The derived wood/PIBOMA composite showed efficient wood structure swelling and possessed outstanding water resistance and low dynamic wettability. Moreover, the 
filled PIBOMA also reinforced the wood scaffold, resulting in a remarkable improvement in MOR and MOE.

3. This work provided a method to improve the water resistance and mechanical properties of fast-growing poplar by using renewable resources (IBOMA). The obtained wood composites have prospective applications in architectural decoration and other fields.

\section{ACKNOWLEDGMENTS}

This authors gratefully acknowledge the financial support by the National Key R\&D Program of China (2017YFD0600205).

\section{REFERENCES CITED}

Brischke, C., and Melcher, E. (2015). "Performance of wax-impregnated timber out of ground contact: Results from long-term field testing," Wood Science and Technology 49(1), 189-204. DOI: 10.1007/s00226-014-0692-6

Chang, H.-T., and Chang, S.-T. (2002). "Moisture excluding efficiency and dimensional stability of wood improved by acylation," Bioresource Technology 85(2), 201-204. DOI: $10.1016 / \mathrm{s} 0960-8524(02) 00085-8$

Chang, H., Tu, K., Wang, X., and Liu, J. (2015). "Facile preparation of stable superhydrophobic coatings on wood surfaces using silica-polymer nanocomposites," BioResources 10(2), 2585-2596. DOI: 10.15376/biores.10.2.2585-2596

Cubbage, F., Mac Donagh, P., Balmelli, G., Olmos, V. M., Bussoni, A., Rubilar, R., De La Torre, R., Lord, R., Huang, J., Hoeflich, V. A., et al. (2014). "Global timber investments and trends, 2005-2011," New Zealand Journal of Forestry Science 44(1), 1-12. DOI: $10.1186 / 1179-5395-44-s 1-s 7$

Ding, W.-D., Koubaa, A., and Chaala, A. (2013). "Mechanical properties of MMAhardened hybrid poplar wood," Industrial Crops and Products 46, 304-310. DOI: 10.1016/j.indcrop.2013.02.004

Dong, X., Sun, T., Liu, Y., Li, C., and Li, Y. (2015). "Structure and properties of polymer-impregnated wood prepared by in-situ polymerization of reactive monomers," BioResources 10(4), 7854-7864. DOI: 10.15376/biores.10.4.7854-7864

Dong, Y., Yan, Y., Zhang, S., and Li, J. (2014). "Wood/polymer nanocomposites prepared by impregnation with furfuryl alcohol and nano-SiO ${ }_{2}$," BioResources 9(4), 6028-6040. DOI: 10.15376/biores.9.4.6028-6040

Dong, Y., Yan, Y., Wang, K., Li, J., Zhang, S., Xia, C., Shi, S. Q., and Cai, L. (2016).

"Improvement of water resistance, dimensional stability, and mechanical properties of poplar wood by rosin impregnation," European Journal of Wood and Wood Products 74(2), 177-184. DOI: 10.1007/s00107-015-0998-6

Dong, Y., Zhang, W., Hughes, M., Wu, M., Zhang, S., and Li, J. (2019). "Various polymeric monomers derived from renewable rosin for the modification of fastgrowing poplar wood," Composites Part B: Engineering 174, Article ID 106902. DOI: 10.1016/j.compositesb.2019.106902

Dubey, P., and Gupta, R. (2017). "Effects of dual bio-fuel (Jatropha biodiesel and 
turpentine oil) on a single cylinder naturally aspirated diesel engine without EGR," Applied Thermal Engineering 115, 1137-1147. DOI:

10.1016/j.applthermaleng.2016.12.125

Emmerich, L., Bollmus, S., and Militz, H. (2019). "Wood modification with DMDHEU (1.3-dimethylol-4.5-dihydroxyethyleneurea)-State of the art, recent research activities and future perspectives," Wood Material Science \& Engineering 14(1), 3-18. DOI: 10.1080/17480272.2017.1417907

Gao, Z., Ma, M., Zhai, X., Zhang, M., Zang, D., and Wang, C. (2015). “Improvement of chemical stability and durability of superhydrophobic wood surface via a film of $\mathrm{TiO}_{2}$ coated $\mathrm{CaCO}_{3}$ micro-/nano-composite particles," RSC Advances 5(79), 63978-63984. DOI: $10.1039 / \mathrm{c} 5 \mathrm{ra0} 4000 \mathrm{k}$

GB/T 1936.2 (2009). "Method for determination of the modulus of elasticity in static bending of wood," Standardization Administration of China, Beijing, China.

GB/T 1935 (2009). "Method of testing in compression perpendicular to grain of wood," Standardization Administration of China, Beijing, China.

Ghorbani, M., Aghmashadi, Z. A., Amininasab, S. M., and Abedini, R. (2019). "Effect of different coupling agents on chemical structure and physical properties of vinyl acetate/wood polymer composites," Journal of Applied Polymer Science 136(19), Article ID 47467. DOI: 10.1002/app.47467

Han, X., Miao, X., Zheng, X., Xing, L., and Pu, J. (2015). "Chemical modification by impregnation of poplar wood with functional composite modifier," BioResources 10(3), 5203-5214. DOI: 10.15376/biores.10.3.5203-5214

Hazarika, A., Mandal, M., and Maji, T. K. (2014). "Dynamic mechanical analysis, biodegradability and thermal stability of wood polymer nanocomposites," Composites Part B: Engineering 60, 568-576. DOI: 10.1016/j.compositesb.2013.12.046

He, Z., Qu, L., Wang, Z., Qian, J., and Yi, S. (2019). "Effects of zinc chloride-silicone oil treatment on wood dimensional stability, chemical components, thermal decomposition and its mechanism," Scientific Reports 9(1), Article Number 1601. DOI:

$10.1038 / \mathrm{s} 41598-018-38317-5$

Himmel, S., and Mai, C. (2015). "Effects of acetylation and formalization on the dynamic water vapor sorption behavior of wood," Holzforschung 69(5), 633-643. DOI: 10.1515/hf-2014-0161

Huang, Y., Fei, B., Yu, Y., and Zhao, R. (2013). "Effect of modification with phenol formaldehyde resin on the mechanical properties of wood from Chinese fir," BioResources 8(1), 272-282. DOI: 10.15376/biores.8.1.272-282

Jiang, H., and Kamdem, D. P. (2004). "Development of poly (vinyl chloride)/wood composites. A literature review," Journal of Vinyl and Additive Technology 10(2), 5969. DOI: $10.1002 / \mathrm{vnl} .20009$

Jiang, T., Gao, H., Sun, J., Xie, Y., and Li, X. (2014). "Impact of DMDHEU resin treatment on the mechanical properties of poplar," Polymers and Polymer Composites 22(8), 669-674. DOI: 10.1177/096739111402200803

Kong, L., Guan, H., and Wang, X. (2018). “In situ polymerization of furfuryl alcohol with ammonium dihydrogen phosphate in poplar wood for improved dimensional stability and flame retardancy," ACS Sustainable Chemistry \& Engineering 6(3), 3349-3357. DOI: 10.1021/acssuschemeng.7b03518

Kowalski, S. J., Kyzioł, L., and Rybicki, A. (2002). "Composite of wood and polymerized methacrylate," Composites Part B: Engineering 33(1), 77-86. DOI: 10.1016/S1359-8368(01)00059-2 
Li, J. Z., Furuno, T., Zhou, W. R., Ren, Q., Han, X. Z., and Zhao, J. P. (2009). "Properties of acetylated wood prepared at low temperature in the presence of catalysts," Journal of Wood Chemistry and Technology 29(3), 241-250. DOI: 10.1080/02773810903009499

Li, Y., Dong, X., Liu, Y., Li, J., and Wang, F. (2011). "Improvement of decay resistance of wood via combination treatment on wood cell wall: Swell-bonding with maleic anhydride and graft copolymerization with glycidyl methacrylate and methyl methacrylate," International Biodeterioration \& Biodegradation 65(7), 1087-1094. DOI: 10.1016/j.ibiod.2011.08.009

Li, Y. F., Dong, X. Y., Lu, Z. G., Jia, W. D., and Liu, Y. X. (2013). "Effect of polymer in situ synthesized from methyl methacrylate and styrene on the morphology, thermal behavior, and durability of wood," Journal of Applied Polymer Science 128(1), 1320. DOI: 10.1002/app.38099

Liu, M. L., Li, C. F., and Liu, Y. L. (2019). "Physical and mechanical properties of modified poplar wood by heat treatment and impregnation of sodium silicate solution," Wood Research 64(1), 145-154.

Nirmala, R., Woo-il, B., Navamathavan, R., Kalpana, D., Lee, Y. S., and Kim, H. Y. (2013). "Influence of antimicrobial additives on the formation of rosin nanofibers via electrospinning," Colloids and Surfaces B: Biointerfaces 104, 262-267. DOI: 10.1016/j.colsurfb.2012.12.014

Pandey, K. K. (1999). "A study of chemical structure of soft and hardwood and wood polymers by FTIR spectroscopy," Journal of Applied Polymer Science 71(12), 19691975. DOI:10.1002/(SICI)1097-4628(19990321)71:12<1969::AID-APP6>3.0.CO;2-D

Qiu, H. B., Yang, S., Han, Y. M., Shen, X. S., Fan, D. B., Li, G. Y., and Chu, F. X. (2018). "Improvement of the performance of plantation wood by grafting water-soluble vinyl monomers onto cell walls," ACS Sustainable Chemistry \& Engineering 6(11), 1445014459. DOI: $10.1021 /$ acssuschemeng.8b03112

Reis, J. P., De Moura, M. F. S. F., Silva, F. G. A., and Dourado, N. (2018). "Dimensional optimization of carbon-epoxy bars for reinforcement of wood beams," Composites Part B: Engineering 139, 163-170. DOI: 10.1016/j.compositesb.2017.11.046

Scholz, G., Militz, H., Gascón-Garrido, P., Ibiza-Palacios, M. S., Oliver-Villanueva, J. V., Peters, B. C., and Fitzgerald, C. J. (2010). "Improved termite resistance of wood by wax impregnation," International Biodeterioration \& Biodegradation 64(8), 688-693. DOI: 10.1016/j.ibiod.2010.05.012

Tao, Y., Li, P., Cai, L., and Shi, S. Q. (2019). "Flammability and mechanical properties of composites fabricated with $\mathrm{CaCO} 3$-filled pine flakes and phenol formaldehyde resin," Composites Part B: Engineering 167, 1-6. DOI: 10.1016/j.compositesb.2018.12.005

Van Gelder, H. A., Poorter, L., and Sterck, F. J. (2006). "Wood mechanics, allometry, and life-history variation in a tropical rain forest tree community," New Phytologist 171(2), 367-378. DOI: 10.1111/j.1469-8137.2006.01757.x

Wang, C. G., Li, R., Liu, C. Q., and Wang, X. D. (2019). "Effects of medium-low temperature hydrothermal treatment on microstructure and dimensional stability of Chinese sweetgum wood," Wood Research 64(1), 97-104. DOI: 10.1002/app.38099

Wang, K., Dong, Y., Yan, Y., Zhang, S., and Li, J. (2018). "Improving dimensional stability and durability of wood polymer composites by grafting polystyrene onto wood cell walls," Polymer Composites 39(1), 119-125. DOI: 10.1002/pc.23912

Wang, K., Dong, Y., Yan, Y., Zhang, W., Qi, C., Han, C., Li, J., and Zhang, S. (2017). "Highly hydrophobic and self-cleaning bulk wood prepared by grafting long-chain 
alkyl onto wood cell walls," Wood Science and Technology 51(2), 395-411. DOI: 10.1007/s00226-016-0862-9

Xie, Y., Fu, Q., Wang, Q., Xiao, Z., and Militz, H. (2013). "Effects of chemical modification on the mechanical properties of wood," European Journal of Wood and Wood Products 71(4), 401-416. DOI: 10.1007/s00107-013-0693-4

$\mathrm{Xu}, \mathrm{X}$. W., Xu, X., Wei, B. S., and Wang, S. F. (2017). "Synthesis and properties of isobornyl methacrylate," Journal of Nanjing Forestry University 37(4), 133-138.

Yang, M. S., Chen, X. Y., Li, J., Lin, H. X., Zhang, S. F., and Han, C. R. (2018). "Preparation of wood with better water-resistance properties by a one-step impregnation of maleic rosin," Journal of Adhesion Science and Technology 32(21), 2381-2393. DOI: 10.1080/01694243.2018.1479211

Article submitted: November 6, 2019; Peer review completed: January 15, 2020;

Revisions accepted: February 7, 2020; Published: February 11, 2020.

DOI: $10.15376 /$ biores. 15.2.2356-2370 